\title{
Anti-oxidant strategies to treat stroke
}

\author{
Bernhard H.J. Juurlink
}

Department of Anatomy and Cell Biology, College of Medicine, University of Saskatchewan, 107 Wiggins Road, Saskatoon, SK, S7N 5E5, Canada

\section{Introduction}

There is an abundance of evidence that there is significant oxidative stress following stroke [1]. Human trials with therapies aimed at reducing oxidative stress have, however, been disappointing. The trials with the 21-aminosteroid tirilazad mesylate suggests that this anti-oxidant therapy does not result in better outcome following stroke [2] and may even result in worse outcome [3]. The reasons for these failures are understandable when pathways of oxidative stress are examined. A consideration of the consequences of oxidative stress at the cellular level and mechanisms used by the cell to minimize oxidative stress ought to provide the theoretical basis for rationally pursuing therapies directed towards minimizing oxidative stress.

\section{Oxidative stress and cell dysfunction}

Strong oxidants such as the hydroxyl radical [4] or peroxynitrous acid [5] can cause polyunsaturated fatty acid peroxidation that, in the presence of oxygen, initiates a self-perpetuating chain reaction of lipid peroxidation causing alterations in membrane fluidity [6], increased permeability of membranes [7] and decreased membrane ATPase activity [8]. This results in increased $\mathrm{Na}^{+}$and $\mathrm{Ca}^{2+}$ influx resulting in depletion of cellular ATP stores and all the problems associated with cellular $\mathrm{Ca}^{2+}$ overload $[9,10]$. Lipid radicals and peroxides also break down (Fig. 1) forming proinflammatory isoprostanes [11] and isoleukotrienes [12] or strong oxidants including dicarbonyls such as malondialdehyde [13] and $\alpha, \beta$-unsaturated aldehydes [14, 15]. The latter are strong oxidants that can interfere with critical cellular functions such as glutamate uptake [14, 16], alter membrane protein configuration [7], interfere with maintenance of ion homeostasis [17], as well as mitochondrial respiration [18]. In addition, other oxidants such as peroxynitrous acid inhibit the activity of the mitochondrial respiratory chain proteins [19].

Oxidative stress can promote activation of pro-inflammatory gene cascades activating nuclear factor $\kappa B(\mathrm{NF}-\kappa \mathrm{B})$, reviewed in [20]. NF- $\mathrm{\kappa B}$ is a transcriptional 
Glyoxalase Inactivation Path

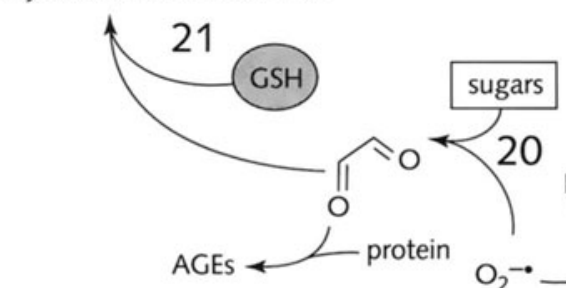

AGEs « L protein

$\mathrm{O}_{2} \cdot$

SOD

$7 \mathrm{NADPH}$

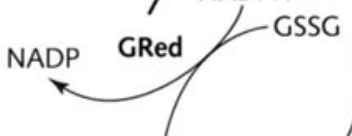

-

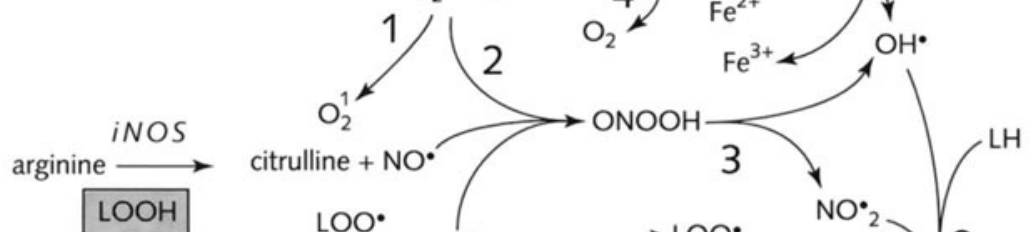

2

4
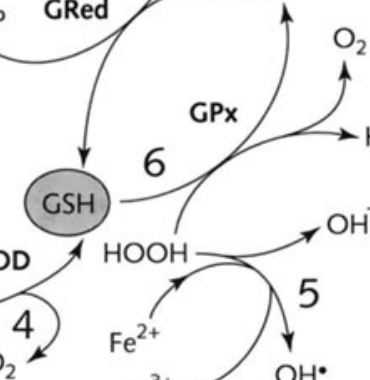

15

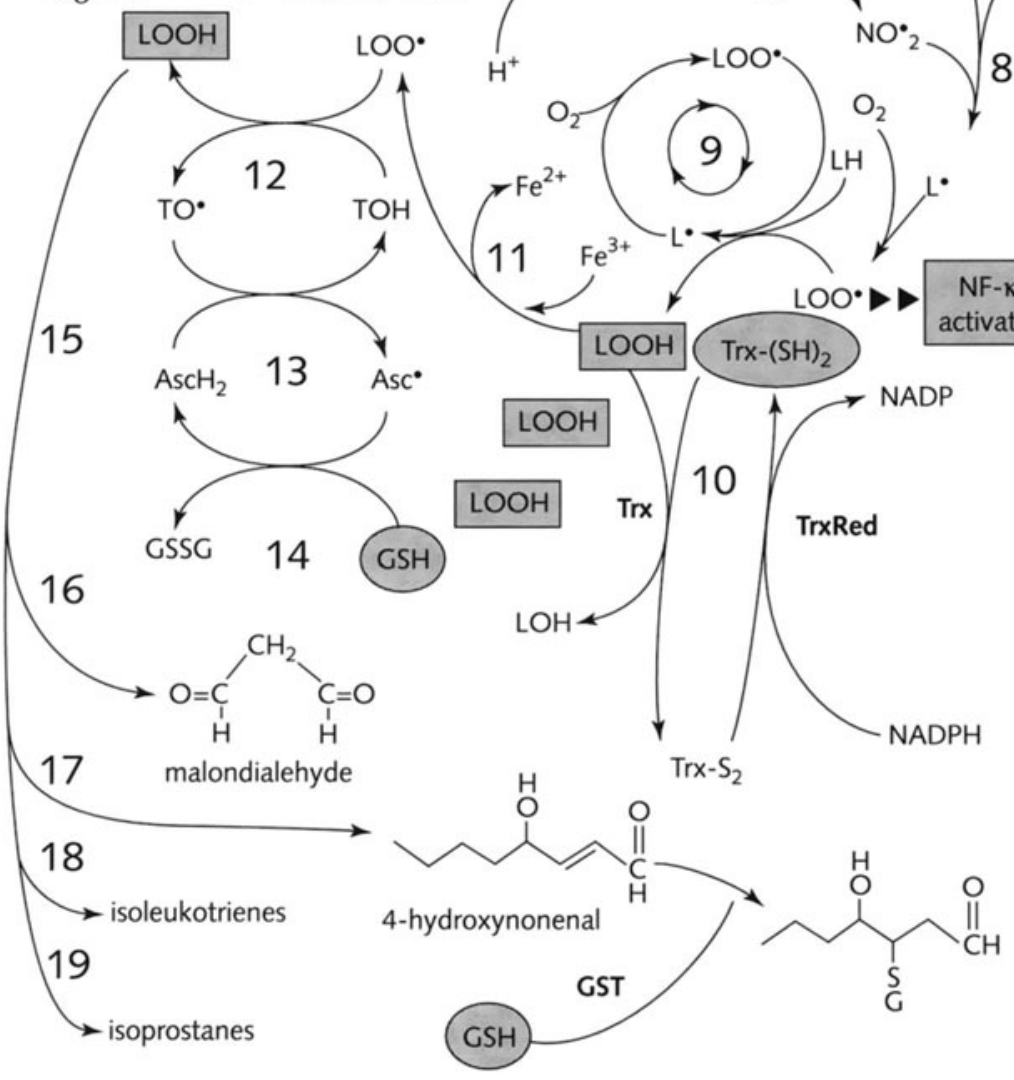


factor complex whose activation is required for maximal transcription of a wide array of pro-inflammatory proteins important in the generation of acute inflammation [21].

\section{Mechanisms of strong oxidant production and scavenging}

\section{Glutathione (GSH)-dependent scavenging mechanisms}

This is illustrated in Figure 1. References for these pathways can be found in [20, 22]. Note that GSH plays important roles in: (1) scavenging peroxides, both hydrogen peroxide and lipid peroxides, catalysed by the selenoproteins glutathione per-

\section{Figure 1}

Some pathways involved in generation and scavenging of strong oxidants. To reduce clutter, the reactions are not necessarily balanced and sometimes leave out intermediate steps. Superoxide can interact with another molecule of superoxide (\#1) to form the strong oxidant, singlet oxygen. Superoxide can also interact with nitric oxide to give rise to peroxynitrous acid (\#2) that in turn can give rise to strong oxidants such as the nitrogen dioxide and hydroxyl radicals (\#3). Hence, superoxide is scavenged by superoxide dismutase (SOD) to form hydrogen peroxide and molecular oxygen (\#4). In the presence of transition metal ions, hydrogen peroxide can give rise to the hydroxyl radical (\#5). Hydrogen peroxide is scavenged by glutathione peroxidase (GPX) that requires GSH as the electron donor (\#6). The oxidized-glutathione is reduced by glutathione reductase (GRed) that uses NADPH as the electron donor (\#7). The hydroxyl radical can abstract an electron from a polyunsaturated fatty acid (LH) to form a carbon-centred lipid radical (\#8). The lipid radical can interact with molecular oxygen to form a peroxyl radical that in turn can abstract an electron from a polyunsaturated fatty acid initiating a lipid peroxidation chain reaction (\#9). The oxidative stress that ensues can activate NF- $\mathrm{KB}$. The lipid peroxides that are formed are scavenged by either thioredoxin reductase using thioredoxin $\left(\operatorname{Tr}\left[\mathrm{SH}_{2}\right)\right.$ as electron donor (\#10) or glutathione peroxidase using GSH as the electron donor (not presented). It is necessary to scavenge the lipid peroxides since they can interact with transition metal ions to give rise to new lipid peroxyl radicals (\#11) that can initiate new rounds of lipid peroxidation. Lipid peroxyl radicals are quenched by vitamin $E(T O H)$ giving rise to an innocuous vitamin E radical (\#12). The vitamin E radical is reduced by ascorbic acid (\#13) and the oxidized ascorbate is reduced by GSH (\#14). Lipid peroxides can also break down (\#15) into: strong oxidants such as malondialdehyde (\#16); 4-hydroxynonenal (\#17) which is scavenged by glutathione S-transferase (GST) by formation of an adduct with GSH; isoleukotrienes (\#18); and isoprostanes (\#19). In the presence of transition metal ions, superoxide anion can also convert sugars to strong oxidants such as the dicarbonyl glyoxal (\#20). Dicarbonyls are scavenged by the glyoxalase pathway that uses GSH as a cofactor (\#21). 
oxidases [23]; (2) the reduction of oxidized ascorbate [24], which is essential for the ultimate regeneration of vitamin E from the vitamin E radical; (3) in neutralizing strong oxidants including $\alpha, \beta$-unsaturated aldehydes such as 4 -hydroxynonenal by forming glutathione adducts catalyzed by various glutathione S-transferases (GSTs) [25]; (4) as an essential cofactor in the scavenging of $\alpha$-oxo-aldehydes such as glyoxal and methylglyoxal [26]. Cellular levels of GSH typically vary from 2-10 mM [27].

Vitamin E, along with ascorbic acid, plays an important, albeit limited, role in peroxide scavenging by inactivating lipid peroxyl radicals, giving rise to innocuous vitamin $\mathrm{E}$ radicals plus lipid hydroperoxides. Inactivation of lipid peroxyl radicals does not eliminate the problems encountered with the lipid peroxidation cascade since lipid hydroperoxides can interact with transition metal ions giving rise to alkoxyl radicals, peroxyl radicals, $\alpha, \beta$-unsaturated aldehydes or reactive aldhehydes such as malondialdehyde and 4-hydroxyalkenals, as well as isoprostanes and isoleukotrienes: this is likely why anti-oxidant approaches such as administering tirilazad mesylate have not been proven to be efficacious treatments for oxidative stress.

\section{Thioredoxin-dependent scavenging mechanisms}

Thioredoxin(Trx)-dependent peroxidases (peroxiredoxins) [28] also scavenge peroxides; the significance of the peroxiredoxins in peroxide scavenging is still not clear. Oxidized-Trx is reduced by the selenoprotein Trx reductase (TrxRed). The typical concentration of $\operatorname{Trx}$ within cells is approximately $10 \mu \mathrm{M}[29,30]$; hence, the efficiency by which Trx-dependent scavenging occurs is dependent upon the ability of the cell to reduce oxidized-Trx. TrxRed has been shown to have a number of other important anti-oxidant functions that include: (1) reduction of the ascorbyl radical [31] as well as oxidized-ascorbate [32] and lipoic acid [33]; and (2) with selenocyst(e)ine as a cofactor, TrxRed can also directly scavenge lipid peroxides [34] as well as peroxynitrite [35].

\section{Central anti-oxidant players}

\section{GSH}

During oxidative stress the ability to synthesize GSH is critical. Regulation of GSH synthesis is complex and involves the following two reactions [36]:

(1) 1-glutamic acid + 1-cysteine + ATP $\leftrightarrow$ 1- $\gamma$-glutamyl-1-cysteine $+\mathrm{ADP}+\mathrm{P}_{\mathrm{i}}$

(2) 1 - $\gamma$-glutamyl-1-cysteine $+\mathrm{ATP}+$ glycine $\leftrightarrow$ glutathione $+\mathrm{ADP}+\mathrm{P}_{\mathrm{i}}$ 
The first reaction, catalyzed by $1-\gamma$-glutamyl-1-cysteine synthase (GCS), is the ratelimiting reaction that is inhibited by GSH with the GSH-dependent inhibition alleviated by glutamate [37]. This first reaction is also rate-limiting in that cysteine is the rate-limiting amino acid. Cellular cysteine content is regulated principally by the uptake of cystine since cysteine is readily auto-oxidized. Cystine is taken up (or released) by the $\mathrm{X}_{\mathrm{c}}^{-}$antiporter in exchange for glutamate [38]; intracellularly, one molecule of cystine is reduced to two molecules of cysteine. The intracellular concentration of glutamate, thus, has a two-fold regulatory effect on intracellular GSH concentration: (1) alleviating the GSH inhibition of GCS, and (2) regulating uptake of cystine.

\section{Phase 2 proteins}

Another approach to increase intracellular GSH is to increase GCS activity. GCS is a heterodimeric enzyme whose 2 subunits are under the control of the anti-oxidant response element (ARE) [39]. The transcription of genes with an ARE in the promoter region can be induced by phase 2 protein inducers. There are a number of compounds (mainly Michael reaction acceptors, quinones and certain isothiocyanates) at low micromolar concentrations that selectively activate the anti-oxidant response; such phase 2 protein-inducing compounds can form components of our diet, see [22]. In addition to GCS, the following proteins belong to the phase 2 protein family: quinone reductase, GSTs, epoxide hydrolase, UDP-glucoronosyltransferase [40], TrxReds, both cytosolic and mitochondrial isoforms [41], inducible heme oxygenase, peroxiredoxin $\mathrm{I}, \mathrm{X}^{-} \mathrm{c}$ cystine/glutamate antiporter [42] and ferritin $\mathrm{H}$ [43].

There has been considerable study of phase 2 enzymes and their induction in the context of cancer prevention, e.g., [44, 45], but little attention has been paid in the context of other diseases. In principle, induction of phase 2 proteins ought to decrease oxidative stress.

\section{Decreasing oxidative stress in the context of stroke}

\section{Stroke prevention}

There is a link between diet and atherosclerosis, with diets high in fruits and vegetables being correlated with lower incidence of heart attacks and stroke [46, 47]. Factors that predispose one to atherogenesis all cause oxidative stress at the level of the endothelium, e.g., hypercholesterolemia, hypertension [48-50], homocysteine [51-55], hyperglycemia associated with diabetes increases the formation of advanced glycation endproducts $[56,57]$ which also causes increases in oxidative 
stress, while bacterial endotoxins activate pro-inflammatory gene expression in endothelial cells [58]. Therefore, decreasing oxidative stress ought to inhibit development of atherosclerosis. I have argued elsewhere [22] that a diet rich in phase 2 protein inducers will possibly inhibit atherogenesis; hence, I shall not dwell at length on this topic.

\section{Decreasing oxidative stress once a stroke has occurred}

One of the problems with nutritional studies in relationship to disease is that such studies tend to focus on one nutritional component without considering the interactions amongst nutritional components. For example, there are many studies on vitamin $\mathrm{E}$ which do not take into consideration the interaction between vitamin $\mathrm{E}$ radical and vitamin $\mathrm{C}$, nor the importance of GSH and selenoproteins in the reduction of oxidized ascorbate and scavenging of the lipid hydroperoxides that are an endproduct of lipid peroxidation.

Nutritional intake of stroke patients is often suboptimal and malnutrition can occur secondary to stroke [59-61]. Following a stroke there is a rapid reduction of plasma anti-oxidants [62]. To date, nutritional support following trauma to the CNS been mainly targeted toward achieving caloric and nitrogen balance to prevent protein-energy malnutrition [63]. It is suggested that following a stroke there be aggressive nutritional intervention that not only targets caloric and nitrogen balance, but also promotes anti-oxidant activities of tissues.

\section{Selenium and vitamins $C$ and $E$}

GPx's and TrxRed's are selenoproteins and the synthesis of these proteins is dependent upon the availability of selenium. Low serum selenium levels are associated with increased risk of stroke [64] and selenium supplementation has been shown to reduce the risk of stroke mortality in one trial [65]. The synthesis of selenoproteins is regulated by availability of dietary selenium [66]. Recommended daily allowance for selenium is $55 \mu \mathrm{g} /$ day (National Academy of Sciences Institute of Medicine's Dietary Reference Intake value) with maximal safe intake being around $400 \mu \mathrm{g} / \mathrm{day}$ [67].

Vitamin E plays an important role in inactivating lipid peroxyl radicals while vitamin $C$ plays an important role in reducing the vitamin $\mathrm{E}$ radical to vitamin $\mathrm{E}$. The blood levels of these anti-oxidant vitamins decrease following a stroke [62]. The recommended daily allowance of vitamin is $15 \mathrm{mg} /$ day of the $R R R$ - $\alpha$-tocopherol/day, while for vitamin $C$ it is 75 and $100 \mathrm{mg} /$ day for females and males respectively with an additional $35 \mathrm{mg} /$ day for smokers.

It is recommended that stroke patients be administered selenium and vitamins $C$ and $\mathrm{E}$ at a dose that is at least the daily recommended allowance. 


\section{GSH}

Factors regulating GSH synthesis are (1) availability cysteine, (2) activity of GCS, and (3) cellular concentration of glutamate since glutamate can (a) promote cystine uptake and (b) alleviate the inhibition of GSH on GCS activity.

\section{Cysteine delivery vehicles}

Since cysteine auto-oxidizes and cystine has low solubility, an efficient way to increase intracellular cysteine is to administer cysteine-containing dipeptides that do not auto-oxidize readily. Thus, $1-\gamma$-glutamyl-1-cysteine and especially $1-c y s t e i n y l-$ glycine [68] have been shown to be efficient ways of increasing neuronal GSH by increasing intracellular cysteine. Dipeptides are increasingly used in clinical nutrition [69] and such dipeptides can be administered enterally or parenterally. A traditional nutritional approach might also be used. For example, an increase in GSH levels in tissues is seen following the consumption of whey [70-73]. The likely explanation for this is that bovine serum albumin has a high content of glutamylcysteine residues that are released from the undenatured, but not denatured, protein as 1- $\gamma$-glutamyl-1-cysteine dipeptides in the gut. Pharmacological approaches might also be used by administering compounds that can be converted to cysteine intracellularly. Two such compounds are $\mathrm{N}$-acetylcysteine (NAC) and 1-2-oxothiazolidine-4-carboxylate (OTC). We have shown that administration of OTC following spinal cord crush injury promotes GSH synthesis, decreases oxidative stress thereby minimizing tissue damage, enabling otherwise paraplegic rats to locomote [74]. OTC has been used in a number of small human clinical trials showing no untoward effects [75-78]. Although studies suggest that the procysteine compound NAC, unlike OTC [80], does not readily cross the blood-brain barrier [79], it has been shown to be neuroprotective following ischemia and reperfusion $[81,82]$ in animal models. NAC is used clinically to treat acetaminophen-induced liver damage [83].

\section{Increasing intracellular glutamate}

Elevating intracellular glutamate promotes (1) cystine uptake and alleviates the glutamate-induced inhibition of GCS activity, and (2) ATP production since it protects against cataplerotic losses of Kreb cycle intermediates. An effective way to do this is to use glutamine as the delivery system since glutamine is readily taken up by cells and converted to glutamate by glutaminase. Since glutamine is somewhat unstable, it can be administered as the dipeptides 1-alanyl-1-glutamine or glycyl-1-glutamine [69]. Rats fed parenterally with glutamine or glutamine-containing dipeptides better maintained liver GSH than non-supplemented animals [84] and also had improved cardiac function following ischemia and reperfusion [85]. 1-Alanyl-1-glutamine supplementation parenterally has been demonstrated to be clinically safe and led to a better nitrogen balance in post-operative human patients with a significant- 
ly better clinical outcome in the supplemented patients as opposed to placebo controls [86]. Although increasing intracellular glutamate may be counter-intuitive, once a stroke has occurred it is not likely to exacerbate damage.

\section{Induction of phase 2 protein}

Increasing phase 2 enzyme proteins decreases oxidative stress via a large number of mechanisms. Inducers of phase 2 proteins are encountered in our diet and have been shown to increase phase 2 enzymes in rats, e.g., ellagic acid [87]; the isothiocyanate sulforaphane [88]; green tea polyphenolics [89]; soy meal [90], likely mediated by genistein [91]; certain polyphenolics in blueberries/cranberries [92]; the flavonol kaempferol [93]; curcumin, a component of turmeric [94]; and the lignan phytoestrogen enterolactone [91], the metabolite of the major flax seed lignan secoisolariciresinol diglucoside (SDG). Administration of dietary phase 2 protein inducers inhibits chemically-induced tumour formation (reviewed in [22]), suggesting that such dietary compounds might also decrease oxidative stress and accompanying inflammation.

\section{Concluding remarks}

There has been an enormous effort to develop drugs that block various glutamate receptors and calcium channels with little therapeutic effects seen in human clinical trials. There has been some effort directed toward minimizing oxidative stress following stroke and trauma; however, most of these efforts have been directed toward stopping the lipid peroxidation chain by scavenging lipid peroxyl radicals and, again, these approaches have not been promising. As can be seen from this review, scavenging lipid radicals does not eliminate the problems associated with lipid peroxides. Promoting scavenging of peroxides is an efficient way to decrease oxidative stress and this may be accomplished, in part, through a nutritional approach. It is suggested that there be an aggressive nutritional intervention following stroke to ensure that there is adequate intake of: (1) sulfur amino acids for glutathione synthesis, (2) vitamins $\mathrm{E}$ and $\mathrm{C}$ enabling efficient quenching of lipid peroxyl radicals, (3) selenium to ensure that there is optimal selenoproteins being synthesized, thus increasing peroxide scavenging efficiency.

It is also recommended that research be carried out on experimental animal models of stroke to determine whether administration of glutamine promotes glutathione synthesis and better maintains energy stores. It is also recommended that the therapeutic potential of phase 2 enzyme inducers be examined experimentally.

It seems most probable that a nutritional approach could be designed to better enable the vascular and the nervous tissues to cope with oxidative stress and decrease damage following a stroke. 


\section{Acknowledgements}

I thank the Medical Research Council of Canada (now the CIHR), the Heart \& Stroke Foundation of Saskatchewan, the Neurotrauma Initiative of Saskatchewan and the Saskatchewan Agriculture Development Fund for supporting my research.

\section{References}

1 Love S (1999) Oxidative stress in brain ischemia. Brain Pathol 9: 119-131

2 Scott P, Barsan W, Frederiksen S, Kronick S, Zink BJ, Domeier RM, Mitchiner JC, Judge FP, Levy RJ, Alexiou A et al (1996) A randomized trial of tirilazad mesylate in patients with acute stroke (RANTTAS). Stroke 27: 1453-1458

3 The Tirilazad Steering Committee (2000) Tirilazad mesylate in acute ischemic stroke: A systematic review. Stroke 31: 2257-2265

4 Braughler JM, Hall ED (1989) Central nervous system trauma and stroke. I. Biochemical considerations for oxygen radical formation and lipid peroxidation. Free Rad Biol Med 6: 289-301

5 Rubbo H, Radi R, Trujillo M, Telleri R, Kalyanaraman B, Barnes S, Kirk M, Freeman BA (1994) Nitric oxide regulation of superoxide and peroxynitrite-dependent lipid peroxidation. Formation of novel nitrogen-containing oxidized lipid derivatives. J Biol Chem 269: 26066-26075

6 McGrath LT, Douglas AF, McClean E, Brown JH, Doherty CC, Johnston GD, Archbold GP (1995) Oxidative stress and erythrocyte membrane fluidity in patients undergoing regular dialysis. Clin Chim Acta 235: 179-188

7 Subramaniam R, Roediger F, Jordan B, Mattson MP, Keller JN, Waeg G, Butterfield DA (1997) The lipid peroxidation product, 4-hydroxy-2-trans-nonenal, alters the conformation of cortical synaptosomal membrane proteins. J Neurochem 69: 1161-1169

8 Rauchova H, Ledvinkova J, Kalous M, Drahota Z (1995) The effect of lipid peroxidation on the activity of various membrane-bound ATPases in rat kidney. Int J Biochem Cell Biol 27: 251-255

9 Hossmann KA (1994) Glutamate-mediated injury in focal cerebral ischemia - the excitotoxin hypothesis revised. Brain Pathol 4: 23-36

10 Siesjö BK, Zhao Q, Pahlmark K, Siesjo P, Katsura K, Folbergrova J (1995) Glutamate, calcium, and free radicals as mediators of ischemic brain damage. Ann Thorac Surg 59: 1316-1320

11 Liu T-Z, Stern A, Morrow JD (1998) The isoprostanes: Unique bioactive products of lipid peroxidation. $J$ Biomed Sc 5: 415-420

12 Harrison KA, Murphy RC (1995) Isoleukotrienes are biologically active free radical products of lipid peroxidation. J Biol Chem 270: 17273-17278

13 Esterbauer H, Zollner H, Schauer RJ (1990) Aldehydes formed by lipid peroxidation: mechanisms of formation, occurrence, and determination. In: C Vigo-Pelfrey (ed): Membrane lipid peroxidation. CRC Press, Boca Raton, FL, 239-268 
14 Springer JE, Azbill RD, Mark RJ, Begley JG, Waeg G, Mattson MP (1997) 4-hydroxynonenal, a lipid peroxidation product, rapidly accumulates following traumatic spinal cord injury and inhibits glutamate uptake. J Neurochem 68: 2469-2476

15 Comporti M (1998) Lipid peroxidation and biogenic aldehydes: from the identification of 4- hydroxynonenal to further achievements in biopathology. Free Radic Res 28: 623-635

16 Blanc EM, Keller JN, Fernandez S, Mattson MP (1998) 4-hydroxynonenal, a lipid peroxidation product, impairs glutamate transport in cortical astrocytes. Glia 22: 149-160

17 Mark RJ, Lovell MA, Markesbery WR, Uchida K, Mattson MP (1997) A role for 4hydroxynonenal, an aldehydic product of lipid peroxidation, in disruption of ion homeostasis and neuronal death induced by amyloid $\beta$-peptide. J Neurochem 68: 255-264

18 Picklo MJ, Amarnath V, McIntyre JO, Graham DG, Montine TJ (1999) 4-Hydroxy2(E)-nonenal inhibits CNS mitochondrial respiration at multiple sites. J Neurochem 72: 1617-1624

19 Brown GC, Bolanos JP, Heales SJR, Clark JB (1995) Nitric oxide produced by activated astrocytes rapidly and reversibly inhibits cellular respiration. Neurosci Lett 193: 201-204

20 Christman JW, Blackwell TS, Juurlink BHJ (2000) Redox regulation of nuclear factor kappa B: Therapeutic potential for attenuating inflammatory responses. Brain Pathol 10: $153-162$

21 Blackwell TS, Christman JW (1997) The role of nuclear factor-kappa B in cytokine gene regulation. Am J Respir Cell Mol Biol 17: 3-9

22 Juurlink BHJ (2001) Therapeutic potential of dietary phase 2 enzyme inducers in ameliorating diseases that have an underlying inflammatory component. Can J Physiol Pharmacol 79: 266-282

23 Flohé L (1989) The selenoprotein glutathione peroxidase. In: D Dolphin, O Avramović, $\mathrm{R}$ Poulson (eds): Glutathione chemical, biochemical, and medical aspects. Part A. Krieger Publishing, Malabar, FL, 643-731

24 Fornai F, Saviozzi M, Piaggi S, Gesi M, Corsini GU, Malvaldi G, Casini AF (1999) Localization of a glutathione-dependent dehydroascorbate reductase within the central nervous system of the rat. Neuroscience 94: 937-948

25 Goon D, Saxena M, Awasthi YC, Ross D (1993) Activity of mouse liver glutathione Stransferases toward trans, trans-muconaldehyde and trans-4-hydroxy-2-nonenal. Toxicol Appl Pharmacol 119: 175-180

26 Thornalley PJ (1998) Glutathione-dependent detoxification of alpha-oxoaldehydes by the glyoxalase system: involvement in disease mechanisms and antiproliferative activity of glyoxalase I inhibitors. Chem Biol Interact 111-112: 137-151

27 Uhlig S, Wendel A (1992) The physiological consequences of glutathione variations. Life Sci 51: 1083-1094

28 Chae HZ, Kang SW, Rhee SG (1999) Isoforms of mammalian peroxiredoxin that reduce peroxides in presence of thioredoxin. Methods Enzymol 300: 219-226 
29 Björnstedt M, Kumar S, Bjorkhem L, Spyrou G, Holmgren A (1997) Selenium and the thioredoxin and glutaredoxin systems. Biomed Environ Sci 10: 271-279

30 Das KC, White CW (1998) Detection of thioredoxin in human serum and biological samples using a sensitive sandwich ELISA with digoxigenin-labeled antibody. J Immunol Methods 211: 9-20

31 May JM, Cobb CE, Mendiratta S, Hill KE, Burk RF (1998) Reduction of the ascorbyl free radical to ascorbate by thioredoxin reductase. J Biol Chem 273: 23039-23045

32 May JM, Mendiratta S, Hill KE, Burk RF (1997) Reduction of dehydroascorbate to ascorbate by the selenoenzyme thioredoxin reductase. J Biol Chem 272: 22607-22610

33 Arner ES, Nordberg J, Holmgren A (1996) Efficient reduction of lipoamide and lipoic acid by mammalian thioredoxin reductase. Biochem Biophys Res Commun 225: 268274

34 Björnstedt M, Hamberg M, Kumar S, Xue J, Holmgren A (1995) Human thioredoxin reductase directly reduces lipid hydroperoxides by NADPH and selenocystine strongly stimulates the reaction via catalytically generated selenols. J Biol Chem 270: 1176111764

35 Arteel GE, Briviba K, Sies H (1999) Function of thioredoxin reductase as a peroxynitrite reductase using selenocystine or ebselen. Chem Res Toxicol 12: 264-129

36 Meister A (1983) Glutathione. Ann Rev Biochem 79: 711-760

37 Deneke SM, Fanburg BL (1989) Regulation of cellular glutathione. Am J Physiol 257: L163-L173

38 Bannai S (1984) Transport of cystine and cysteine in mammalian cells. Biochim Biophys Acta 779: 289-306

39 Galloway DC, Blake DG, Shepherd AG, McLellan LI (1997) Regulation of human gamma-glutamylcysteine synthetase: co-ordinate induction of the catalytic and regulatory subunits in HepG2 cells. Biochem J 328: 99-104

40 Prestera T, Holtzclaw WD, Zhang Y, Talalay P (1993) Chemical and molecular regulation of enzymes that detoxify carcinogens. Proc Natl Acad Sci USA 90: 2965-2969

41 Eftekharpour E, Holmgren A, Juurlink BHJ (2000) Thioredoxin reductase and glutathione synthesis is upregulated by t-butylhydroquinone in cortical astrocytes but not in cortical neurons. Glia 31: 241-248

42 Ishii $\mathrm{T}$, Itoh K, Sato H, Bannai S (1999) Oxidative stress-inducible proteins in macrophages. Free Radic Res 31: 351-355

43 Tsuji Y, Ayaki H, Whitman SP, Morrow CS, Torti SV, Torti FM (2000) Coordinate transcriptional and translational regulation of ferritin in response to oxidative stress. $\mathrm{Mol}$ Cell Biol 20: 5818-5827

44 Benson AM, Hunkeler MJ, Talalay P (1980) Increase of $\mathrm{NAD}(\mathrm{P})$ :quinone reductase by dietary antioxidants: possible role in protection against carcinogenesis. Proc Natl Acad Sci USA 77: 5216-5220

45 Prestera T, Zhang Y, Spencer SR, Wilczak CA, Talalay P (1993) The electrophile counterattack response: protection against neoplasia and toxicity. Advan Enzym Reg 33: 281-296 
46 Keli SO, Hertog MG, Feskens EJ, Kromhout D (1996) Dietary flavonoids, antioxidant vitamins, and incidence of stroke: the Zutphen study. Arch Intern Med 156: 637-642

47 Yochum L, Kushi LH, Meyer K, Folsom AR (1999) Dietary flavonoid intake and risk of cardiovascular disease in postmenopausal women. Am J Epidemiol 149: 943-949

48 Nakazono K, Watanabe N, Matsuno K, Sasaki J, Sato T, Inoue M (1991) Does superoxide underlie the pathogenesis of hypertension? Proc Natl Acad Sci USA 88: 1004510048

49 Ohara Y, Peterson TE, Harrison DG (1993) Hypercholesterolemia increases endothelial superoxide anion production. J Clin Invest 91: 2546-2551

50 Quyyumi AA (1998) Endothelial function in health and disease: new insights into the genesis of cardiovascular disease. Am J Med 105: 32S-39S

51 Stamier JS, Osborne JA, Jaraki O, Rabbani LE, Mullins M, Singel D, Loscalzo LE (1993) Adverse vascular effects of homocysteine are modulated by endothelium-derived relaxing factor and related oxides of nitrogen. J Clin Invest 91: 308-318

52 Loscalzo J (1996) The oxidant stress of hyperhomocyst(e)inemia. J Clin Invest 98: 5-7

53 Welch GN, Upchurch GR, Jr., Loscalzo J (1997) Homocysteine, oxidative stress, and vascular disease. Hosp Pract (Off Ed) 32: 81-82, 85, 88-92

54 de Jong SC, van den Berg M, Rauwerda JA, Stehouwer CD (1998) Hyperhomocysteinemia and atherothrombotic disease. Semin Thromb Hemost 24: 381-385

55 Hempel SL, Moses BL, O’Malley YQ (1998) Mixed disulfides of homocysteine and cysteine inhibit cystine uptake, decreasing intracellular glutathione. Free Rad Biol Med 25: S33

56 Brownlee M (1995) Advanced protein glycosylation in diabetes and aging. Ann Rev Med 46: 223-234

57 Cooper ME, Gilbert RE, Jerums G (1997) Diabetic vascular complications. Clin Exp Pharmacol Physiol 24: 770-775

58 Seitz CS, Kleindienst R, Xu QB, Wick G (1996) Coexpression of heat-shock protein 60 and intercellular-adhesion molecule-1 is related to increased adhesion of monocytes and $\mathrm{T}$ cells to aortic endothelium of rats in response to endotoxin. Lab Invest 74: 241-252

59 Paterson PG, Juurlink BHJ (1999) Nutritional regulation of glutathione in stroke. Neurotoxicity Res 1: 99-112

60 Gariballa SE (2000) Nutritional factors in stroke. Br J Nutr 84: 5-17

61 Finestone HM (2000) Safe feeding methods in stroke patients. Lancet 355: 1662-3

62 Cherubini A, Polidori MC, Bregnocchi M, Pezzuto S, Cecchetti R, Ingegni T, di Iorio A, Senin U, Mecocci P (2000) Antioxidant profile and early outcome in stroke patients. Stroke 31: 2295-2300

63 Roberts PM (1995) Nutrition in the head-injured patient. New Horiz 3: 506-517

64 Virtamo J, Valkeila E, Alfthan G, Punsar S, Huttunen JK, Karvonen MJ (1985) Serum selenium and the risk of coronary heart disease and stroke. Am J Epidemiol 122: 276282

65 Mark SD, Wang W, Fraumeni JF, Jr., Li JY, Taylor PR, Wang GQ, Dawsey SM, Li B, Blot 
WJ (1998) Do nutritional supplements lower the risk of stroke or hypertension? Epidemiology 9: 9-15

66 Burk RF, Hill KE (1993) Regulation of selenoproteins. Ann Rev Nutr 13: 65-81

67 Yang GQ, Xia YM (1995) Studies on human dietary requirements and safe range of dietary intakes of selenium in China and their application in the prevention of related endemic diseases. Biomed Environ Sci 8: 187-201

68 Dringen R, Pfeiffer B, Hamprecht B (1999) Synthesis of the antioxidant glutathione in neurons: supply by astrocytes of CysGly as precursor for neuronal glutathione. $\mathrm{J} \mathrm{Neu}$ rosci 19: 562-569

69 Fürst P, Kuhn KS (2000) Amino-acid substrates in new bottles: implications for clinical nutrition in the 21st century. Nutrition 16: 603-606

70 Bounous G, Gervais F, Amer V, Batist G, Gold P (1989) The influence of dietary whey protein on tissue glutathione and the diseases of aging. Clin Invest Med 12: 343-349

71 Zommara M, Toubo H, Sakono M, Imaizumi K (1998) Prevention of peroxidative stress in rats fed on a low vitamin E-containing diet by supplementing with a fermented bovine milk whey preparation: effect of lactic acid and beta-lactoglobulin on the antiperoxidative action. Biosci Biotechnol Biochem 62: 710-717

72 Lands LC, Grey VL, Smountas AA (1999) Effect of supplementation with a cysteine donor on muscular performance [published erratum appears in J Appl Physiol 2000 Jan; 88 (1): following table of contents]. J Appl Physiol 87: 1381-1385

73 Lothian B, Grey V, Kimoff RJ, Lands LC (2000) Treatment of obstructive airway disease with a cysteine donor protein supplement: a case report. Chest 117: 914-916

74 Kamencic H, Griebel RW, Lyon A, Paterson PG, Juurlink. BHJ (2001) Promoting glutathione synthesis following spinal cord trauma decreases secondary damage and promotes retention of function. FASEB J 15: 243-250

75 Kalayjian RC, Skowron G, Emgushov R-T, Chance M, Spell SA, Borum PR, Webb LS, Mayer KH, Jackson LB, Yen-Lieberman B et al (1994) A phase I/II trial of intravenous L-2-oxothiazolidine-4-carboxylic acid (Procysteine) in asymptomatic HIV-infected subjects. J Acquir Immune Defic Syndr 7: 369-374

76 Barditch-Crovo P, Noe D, Skowron G, Lederman M, Kalayjian RC, Borum P, Buier R, Rowe WB, Goldberg D, Lietman P (1998) A phase I/II evaluation of oral L-2-oxothiazolidine-4-carboxylic acid in asymptomatic patients infected with human immunodeficiency virus. J Clin Pharmacol 38: 357-363

77 Bernard GR, Wheeler AP, Arons MM, Morris PE, Paz HL, Russell JA, Wright PE (1997) A trial of antioxidants $\mathrm{N}$-acetylcysteine and procysteine in ARDS. The Antioxidant in ARDS Study Group. Chest 112: 164-172

78 Vita JA, Frei B, Holbrook M, Gokce N, Leaf C, Keaney JF (1998) L-2-oxothiazolidine4-carboxylic acid reverses endothelial dysfunction in patients with coronary artery disease. J Clin Invest 101: 1408-1414

79 McLellan LI, Lewis AD, Hall DJ, Ansell JD, Wolf CR (1995) Uptake and distribution of $\mathrm{N}$-acetylcysteine in mice: tissue-specific effects on glutathione concentrations. Carcinogenesis 16: 2099-2106 
80 Anderson ME, Meister A (1989) Marked increase of cysteine levels in many regions of the brain after administration of 2-oxothiazolidine-4-carboxylate. FASEB J 3: 16321636

81 Carroll JE, Howard EF, Hess DC, Wakade CG, Chen Q, Cheng C (1998) Nuclear factor-kappa B activation during cerebral reperfusion: effect of attenuation with $\mathrm{N}$-acetylcysteine treatment. Brain Res Mol Brain Res 56: 186-191

82 Cuzzocrea S, Mazzon E, Costantino G, Serraino I, Dugo L, Calabro G, Cucinotta G, De Sarro A, Caputi AP (2000) Beneficial effects of $\mathrm{N}$-acetylcysteine on ischaemic brain injury. Br J Pharmacol 130: 1219-1226

83 Speeg KV, Bay MK (1995) Prevention and treatment of drug-induced liver disease. Gastroenterol Clin North Am 24: 1047-1064

84 Matilla B, Ortiz J, Gonzalez P, Garcia-Diez F, Jorquera F, Culebras JM, Gonzalez-Gallego J, Tunon MJ (2000) Effects of parenteral nutrition supplemented with glutamine or glutamine dipeptides on liver antioxidant and detoxication systems in rats. Nutrition 16: 125-128

85 Khogali SE, Harper AA, Lyall JA, Rennie MJ (1998) Effects of L-glutamine on postischaemic cardiac function: protection and rescue. J Mol Cell Cardiol 30: 819-827

86 Jian ZM, Cao JD, Zhu XG, Zhao WX, Yu JC, Ma EL, Wang XR, Zhu MW, Shu H, Liu YW (1999) The impact of alanyl-glutamine on clinical safety, nitrogen balance, intestinal permeability, and clinical outcome in postoperative patients: a randomized, doubleblind, controlled study of 120 patients. JPEN J Parenter Enteral Nutr 23: S62-S66

87 Barch DH, Rundhaugen LM, Pillay NS (1995) Ellagic acid induces transcription of the rat glutathione S-transferase-Ya gene. Carcinogenesis 16: 665-668

88 Fahey JW, Zhang Y, Talalay P (1997) Broccoli sprouts: an exceptionally rich source of inducers of enzymes that protect against chemical carcinogens. Proc Natl Acad Sci USA 94: 10367-10372

89 Khan SG, Katiyar SK, Agarwal R, Mukhtar H (1992) Enhancement of antioxidant and phase II enzymes by oral feeding of green tea polyphenols in drinking water to SKH-1 hairless mice: possible role in cancer chemoprevention. Cancer Res 52: 4050-4052

90 Appelt LC, Reicks MM (1997) Soy feeding induces phase II enzymes in rat tissues. Nutr Cancer 28: 270-275

91 Wang W, Liu LQ, Higuchi CM, Chen H (1998) Induction of NADPH:quinone reductase by dietary phytoestrogens in colonic Colo205 cells. Biochem Pharmacol 56: 189-195

92 Bomser J, Madhavi DL, Singletary K, Smith MA (1996) In vitro anticancer activity of fruit extracts from Vaccinium species. Planta Med 62: 212-216

93 Uda Y, Price KR, Williamson G, Rhodes MJ (1997) Induction of the anticarcinogenic marker enzyme, quinone reductase, in murine hepatoma cells in vitro by flavonoids. Cancer Lett 120: 213-216

94 Dinkova-Kostova AT, Talalay P (1999) Relation of structure of curcumin analogs to their potencies as inducers of Phase 2 detoxification enzymes. Carcinogenesis 20: 911-914 